\title{
Processamento e aceitação sensorial do hambúrguer de coelho (Orytolagus cunicullus)
} Processing and sensorial acceptance of rabitt hamburguer

\author{
Rodrigo de Souza TAVARES ${ }^{1}$, Adriano Gomes da CRUZ ${ }^{1 *}$, Thiago Silva de OLIVEIRA ${ }^{1}$, \\ Aline Rosa BRAGA ${ }^{1}$, Fernanda Almeida dos REIS ${ }^{1}$, Iracema Maria Carvalho da HORA ${ }^{1}$, \\ Rosângela da Costa TEIXEIRA ${ }^{1}$, Edmir Fernandes FERREIRA ${ }^{1}$
}

\begin{abstract}
Resumo
O objetivo deste trabalho é verificar a potencialidade do aproveitamento tecnológico da carne do coelho, através do processamento de hambúrguer, e submeter o produto a análises físico-químicas (composição centesimal) e sensorial (teste de aceitabilidade, representado por Escala Hedônica de sete pontos). Os resultados obtidos para as análises físico-químicas foram: Umidade $(68,34 \pm 0,80) \%$, Cinzas $(1,01 \pm 0,06) \%$, Proteínas $(18,37 \pm 0,03) \%$, Lipídios $(3,59 \pm 0,04) \%$ e Carboidratos $(8,69 \pm 0,07) \%$ resultados estes condizentes com a legislação. A análise sensorial indicou uma ótima aceitação do produto, obtendo média de 5,85 classificando o produto entre os pontos "gostei moderadamente" e "gostei muito". Os resultados confirmam o potencial tecnológico da carne de coelho para a elaboração de produtos cárneos, e sua viabilidade de produção e comercialização para consumo humano.

Palavras-chave: coelho; hambúrguer; qualidade; processamento.
\end{abstract}

\begin{abstract}
This study consisted of an evaluation of the technological potential of rabbit meat processed into hamburger, and its physicochemical and sensorial analysis. The physicochemical analyses indicated the following contents: moisture $(68.34 \pm 0.80) \%$, ashes $(1.01 \pm 0.06) \%$, proteins $(18.37 \pm 0.03) \%$, lipids $(3.59 \pm 0.04) \%$ and carbohydrates $(8.69 \pm 0.07) \%$, all of which meet the requirements of Brazilian legislation. The sensorial analysis indicated excellent acceptance of the product, with an average score of 5.85, classifying it as "like it moderately" and "like it very much." The results confirm the technological potential of rabbit as a food product, and the viability of its production, processing and commercialization for human consumption.

Keywords: rabbit meat; hamburger; quality; processing.
\end{abstract}

\section{Introdução}

Produtos cárneos processados ou preparados são aqueles cujas características originais da carne fresca foram alteradas através de tratamentos físicos e/ou químicos. O processamento da carne fresca visa à elaboração de novos produtos e, por sua ação sobre enzimas de microorganismos de caráter degradativo, prolongamento da vida de prateleira. Ele não modifica de forma significativa as características nutricionais, mas atribui características organolépticas como cor, sabor e próprias de cada processo $^{9}$.

A carne de coelho apresenta um excelente potencial para a produção de derivados cárneos. Possui elevado valor biológico porque contém aminoácidos essenciais, além de possuir altos teores de potássio, fósforo e magnésio; sendo recomendada para crianças, idosos, convalescentes e pessoas que buscam uma dieta saudável. Possui elevado valor protéico (19 a 23\%), baixo teor de gordura (3-6\% contra 9-10\% do frango) e baixo

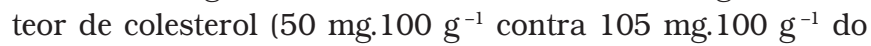
frango) e, com isso, representa uma excelente opção para pessoas que buscam uma dieta saudável com baixo conteúdo calórico $^{3}$. Estudos anteriores relatam para a carne de coelho, valores médios de umidade, proteínas, lipídios e colesterol de $70,8,21,3,6,8$ e 0,053 g. $100 \mathrm{~g}^{-1}$, respectivamente ${ }^{13}$.

Recebido para publicação em 6/11/2006

Aceito para publicação em 31/5/2007 (002029)

${ }^{1}$ Curso Técnico de Química Industrial,

Centro Federal de Educação Tecnológica de Química de Nilópolis - CEFET

Rua Lucio Tavares, 1045, Centro, CEP 26530-060, Nilópolis - RJ, Brasil,

E-mail:food@globo.com

* A quem a correspondência deve ser enviada
Como se trata de uma carne muito saborosa, ela é consumida em grande escala por toda a Europa, principalmente na França e na Espanha, que são os maiores produtores de carne de coelho no mundo. Além deles, os Estados Unidos, como maior produtor mundial, são os principais centros consumidores deste tipo de carne. No Brasil, o consumo de carne de coelho é insignificante, devido à pequena produção, com estimativa anual de 240/250 toneladas. VIEIRA ${ }^{12}$ aponta como fatores responsáveis por esta situação o pequeno volume de produção e a falta de organização no setor, que não vem conseguindo difundir o hábito do consumo e nem mesmo divulgar as grandes qualidades desta carne.

Poucos são os trabalhos citados na literatura com relação ao processamento da carne de coelho. SEEN et al. ${ }^{10}$ utilizaram carnes de coelho, carneiro e combinação das duas em diferentes proporções na formulação de salsichas, verificando que o produto formulado exclusivamente com carne de coelho apresentou maior capacidade de retenção de água, emulsão mais firme e menor teor lipídico. LEE e CHEONG ${ }^{5}$ prepararam salsichas e embutidos mistos de carne suína e de coelho, por substituição do primeiro em quantidades de 0, 20, 40 e $60 \%$ do segundo, não obtendo diferenças significativas entre os produtos desenvolvidos quanto à textura e coesividade.

Desta forma, objetivou-se neste trabalho a verificação do potencial do aproveitamento tecnológico da carne do coelho, através do processamento de hambúrguer e submissão do produto a análises físico-químicas e análise sensorial para sua caracterização e verificação de sua aceitabilidade pelo consumidor. 


\section{Material e métodos}

\subsection{Cálculo do rendimento da carcaça}

O rendimento da carcaça foi realizado dividindo o peso de carne obtido após a desossa pelo peso do animal vivo.

\subsection{Processamento do hambúrguer}

Foram utilizados dois coelhos da raça Nova Zelândia com idade de 45 dias, pesando em média $3,1 \mathrm{~kg}$, provenientes da Universidade Federal Rural do Rio de Janeiro (UFRRJ). Os animais foram abatidos, sendo posteriormente desossados e retiradas as aparas. Obteve-se 1,6 kg de carne que foi submetida a duas etapas de trituração em moedor doméstico. Na segunda etapa, foram adicionados os seguintes ingredientes: cebola, reforçador de sabor, pimenta, proteína de soja e farinha de trigo. Após a mistura, foi realizada a moldagem em hamburgueira doméstica e a embalagem em filmes plásticos para subseqüente acondicionamento em formas de aço inox e congelamento em freezer, a $-10{ }^{\circ} \mathrm{C}$. Todo o processamento foi realizado no Laboratório de Pesquisas Multidisciplinar do CEFET/Química de Nilópolis, sendo a formulação do produto desenvolvida pelos próprios autores a partir de testes preliminares.

\subsection{Análises físico-químicas}

As análises físico-químicas consistiram em composição centesimal sendo realizadas no laboratório de Bromatologia do CEFET/Química do Rio de Janeiro de acordo com a metodologia do INSTITUTO ALDOLFO LUTZ ${ }^{4}$.

\subsection{Análise sensorial}

A análise sensorial foi realizada 48 horas após o processamento, em cabines montadas no pátio do CEFET/Química de Nilópolis com 168 consumidores não-treinados, selecionados previamente devido a sua preferência por consumir produtos cárneos e disponibilidade e interesse em participar do teste. Foi empregada a Escala Hedônica, com escala de aceitabilidade estruturada de 7 pontos $\mathrm{O}$ hambúrguer foi servido após fritura em óleo vegetal, tal como hambúrguer comercial, em cubos de aproximadamente $1,5 \mathrm{~cm}$ de lado. Verificou-se ainda a intenção de compra e freqüência de consumo, além da opinião sobre a cor, odor, textura e sabor do produto ${ }^{4}$.

\section{Resultados e discussão}

\subsection{Rendimento da carcaça}

O rendimento da carcaça foi estimado em $51,61 \%$, estando abaixo do valor informado por MILITIS et al. (2000), citado por ZOTTE ${ }^{13}$ que se situa na faixa de $55-61 \%$ do peso vivo do animal.

\subsection{Análises físico-químicas}

A Tabela 1 mostra os resultados das análises físicoquímicas executadas no hambúrguer de carne de coelho. Os resultados obtidos sugerem um produto com baixo conteúdo de gordura $(3,59 \pm 0,04) \%$, conferindo à carne de coelho um status de carne magra, e indo ao encontro do desejo dos consumidores de ingerirem alimentos com baixo teor lipídico e alto teor protéico $(18,37 \pm 0,03) \%$.

Tabela 1. Composição centesimal do hambúrguer de coelho*.

\begin{tabular}{lc}
\hline Componentes & Média \pm desvio padrão(\%) \\
\hline Proteínas & $18,37 \pm 0,03$ \\
Lipídios & $3,59 \pm 0,04$ \\
Cinzas & $1,01 \pm 0,06$ \\
Umidade & $68,34 \pm 0,80$ \\
Carboidratos & $8,69 \pm 0,07$ \\
\hline *Análises realizadas em triplicata.
\end{tabular}

O produto está de acordo com o Regulamento Técnico de Identidade e Qualidade do Hambúrguer ${ }^{2}$, que estabelece um teor mínimo de $15 \%$ para proteínas e máximo de $23 \%$ para gordura, confirmando as vantagens nutricionais desta carne. Eles estão abaixo dos valores encontrados em outros trabalhos realizados visando à produção de hambúrguer, utilizando outras espécies como matéria-prima. MOURA et al. ${ }^{8}$ encontraram valores de 5,08\% para lipídios e 16,93\% para proteína no desenvolvimento do babybúrguer, hambúrguer elaborado com carne de búfalo usando corte secundário. ROMANELLI, CASERI e LOPES FILHO ${ }^{9}$ encontraram valores de $4,19 \%$ de lipídios e 19,44\% de proteínas para o hambúrguer processado com carne de jacaré. ARISSETO e POLONIO ${ }^{1}$ relataram que, na elaboração de um hambúrguer calabresa, encontraram um teor de $7.4 \%$ de lipídios e 18,8\% de proteínas. Entretanto, MANCHA $^{6}$ relatou um teor de gordura de $1,75 \%$ no desenvolvimento de hambúrguer de carne caprina. SIQUEIRA et al. ${ }^{11}$ encontraram teores de gordura, proteína e umidade na faixa de $2,1-2,6 \%, 17,8-19,5 \%$ e $77,1-77,7 \%$, respectivamente, no desenvolvimento de um hambúrguer bovino de baixo teor de gordura, utilizando carne de soja e como amido modificado e proteína de soja.

\subsection{Análise sensorial}

As Figuras 1, 2, 3 e 4 mostram a performance obtida pelo hambúrguer de coelho na análise sensorial. Foi notada uma ótima aceitação do produto, sendo registrada a média de $5,85 \pm 0,89$, classificando o produto entre os pontos "gostei moderadamente" e "gostei muito", resultado superior ao registrado por ROMANELLI, CASERI e LOPES FILHO ${ }^{9}$, que obtiveram nota 4,84 para o hambúrguer de jacaré e um grande número de comentários desfavoráveis, do tipo "duro" e "apimentado". O produto apresentou intenção de compra por parte de 92,26\% dos consumidores, contra 7,74\% emitindo opinião contrária sobre a compra do produto. Quanto à possível freqüência de consumo do produto, os resultados também se mostraram positivos: $45,83 \%$ declararam que consumiriam o produto semanalmente, $30,95 \%$ mensalmente, $22,02 \%$ raramente e $1,19 \%$ nunca.

Os atributos do produto (cor, sabor, odor e textura) foram considerados bons por $89,29,78,57,81,55$ e $81,55 \%$ dos 


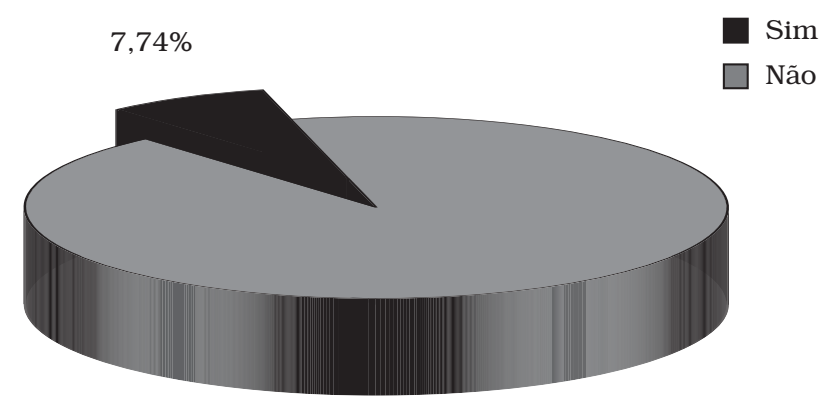

$92,26 \%$

Figura 1. Intenção de compra do hambúrguer de coelho.

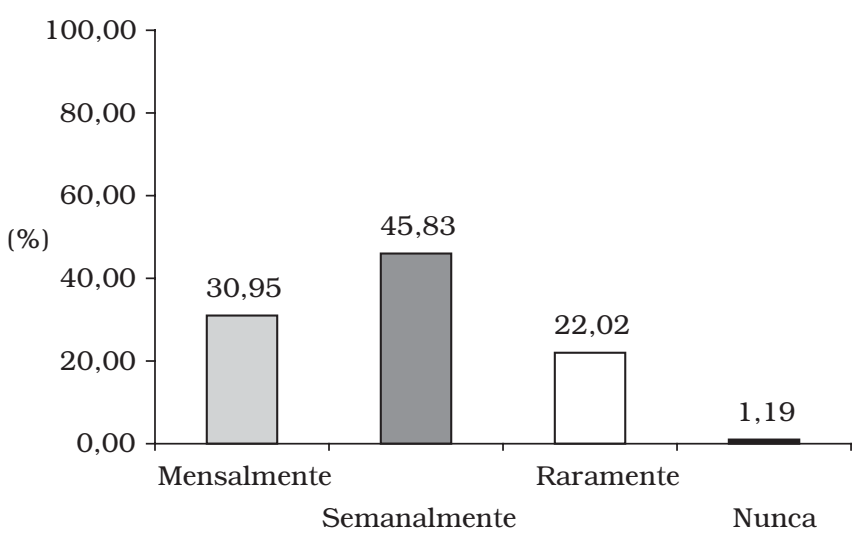

Figura 2. Freqüência de compra do produto.

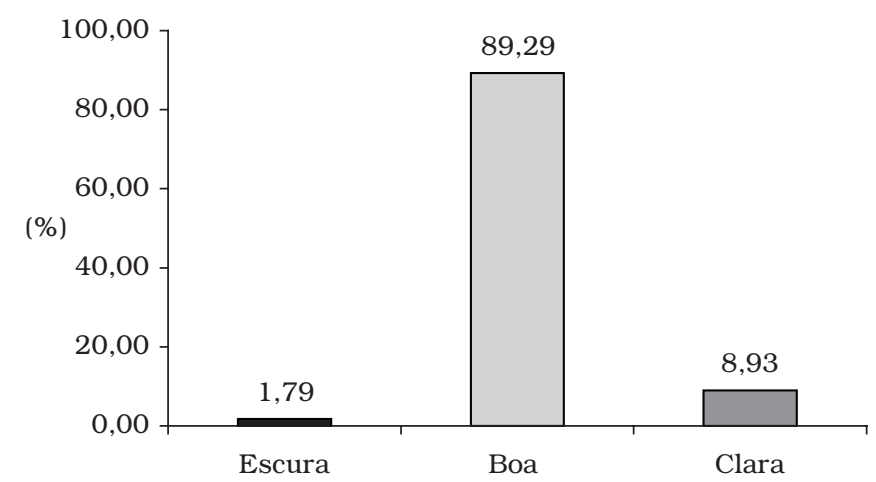

Figura 3. Aceitação do hambúrguer de coelho (cor).

consumidores, respectivamente, conforme é demonstrado nas Figuras 3 e 4 . Esses valores são considerados extremamente satisfatórios, na medida em que os participantes do teste sensorial são, em sua grande parte jovens, freqüentadores de fast-food, consumindo, portanto, sanduíches em que o hambúrguer é ingrediente fundamental. Um comentário apontado pelo painel ressaltou "falta de sal", problema este que pode ser facilmente resolvido pela dosagem do tempero e o acréscimo deste ingrediente na formulação. Embora todos tivessem sido previamente avisados de que se tratava de hambúrguer de

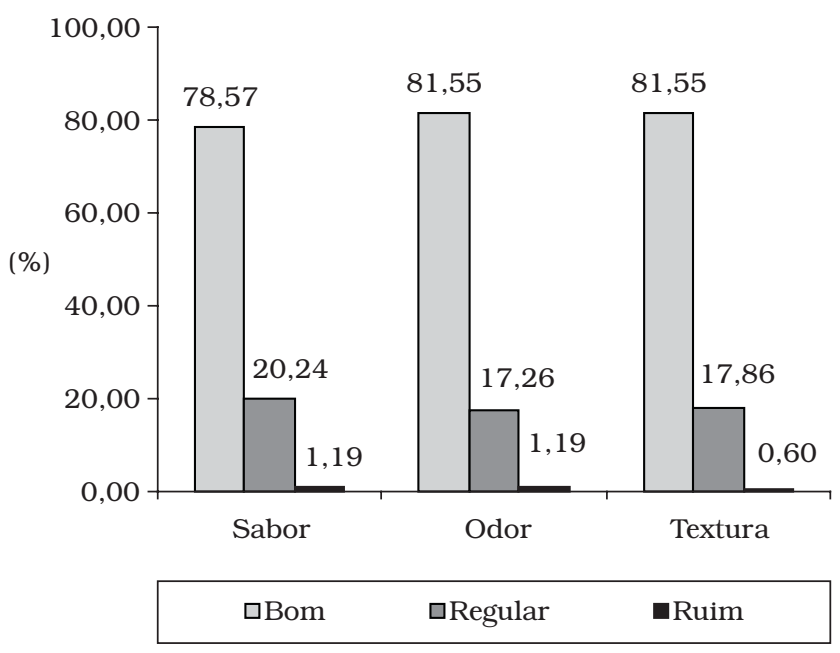

Figura 4. Aceitação do hambúrguer de coelho (sabor, odor e textura).

coelho, mais de $50 \%$ dos participantes associaram o produto ao hambúrguer de frango. É importante ressaltar que nenhum comentário negativo relacionado com os respectivos atributos do produto foi emitido.

\section{Conclusão}

Os resultados deste estudo confirmam o potencial tecnológico da carne de coelho para a elaboração de produtos cárneos, em particular tipo hambúrguer, e sua viabilidade de produção e comercialização para consumo humano. Contudo, estudos adicionais tornam-se necessários visando à otimização de tecnologia de processamento e desenvolvimento de novas formulações.

\section{Referências bibliográficas}

1. ARISSETO, A. P.; POLlONiO, M. A. R. Desenvolvimento e aceitação das características do hambúrguer tipo calabresa. In: Encontro Nacional de Analistas de Alimentos, Rio de Janeiro, 13, 2003. Resumos... Rio de Janeiro: ENAAL, 2003. p. 133.

2. BRASIL. Ministério da Saúde. Agência Nacional de Vigilância Sanitária. Instrução Normativa $n^{\circ}$ 20/2000. Regulamento Técnico de Identidade e Qualidade do Hambúrguer. Disponível em <http://www.agricultura.gov.br>. Acesso em: 23/10/2002.

3. GRANJA DE COELhOS. A carne de coelho. Disponível em <www.chez.com.br/agranjadecoelhos/qualidadesdacarne.htm.> Acesso em 1/11/ 2002.

4. INSTITUTO ADOLF LUTZ. Normas Analíticas do Instituto Adolfo Lutz: métodos químicos e físico para análise de alimentos. 2. ed, volume 1. São Paulo, 1996. 457 p.

5. LEE, K. W.; CHEONG, S. K. Studies on the utilization of rabbit meat for sausage making. The Research Reports of the Office of Rural Development. Livestock and Veterinary, v. 32, n.1, p. 84-88, 1982.

6. MANCHA, M. B. A. Pesquisadora desenvolve hambúrguer de bode. Revista Nacional da Carne, n. 270, p. 40-41, 1999.

7. MODESTA, R. C. D. Manual de Análise Sensorial de Alimentos e Bebidas. Rio de Janeiro: Embrapa/CTAA, 1994. 200 p. 
8. MOURA, M. M. et al. Rendimento e Características Físico-Químicas de "Babyburguer" elaborado com corte secundário de Baby Búfalo. Revista Nacional da Carne, n. 266, p. 301-302, 1998.

9. ROMANELLI, P. F.; CASERI, R.; LOPES FILHO, J. F. Processamento da Carne de Jacaré do Pantanal (Caiman crocodilus yacare). 2002. Ciência e Tecnologia de Alimentos, v. 22, n. 1, p. 70-5, 2002.

10. SEEN, A. R. Comparison of mutton, rabbit and their combinations of meats for sausage processing. Journal of Food Science and Technology. v. 36, n. 5, p. 463-5, 1999.
11. SIQUEIRA, P. B. et al. Desenvolvimento e Aceitação de Hambúrguer com Baixo Teor de Gordura. Food Ingredients, n. 14, p. 74-7, 2001.

12. VIEIRA, M. I. A carne de coelho. Disponível em <www.ruralnews. com.br>. Acessado em 14/03/ 2003.

13. ZOTTE, A. D. Perception of Rabbit Quality and major factors influencing the rabbit carcass and meat quality. Livestock Production Science, n. 75, p. 11-32, 2002. 